ISBN 978-93-84422-76-9

International Conference on Research \& Innovation in Environment, Civil and Architecture Engineering

(RIECAE-17)

Bangkok (Thailand), Feb. 6-7, 2017

\title{
An Experiment on Tension Stiffening Effects of High Strength Concrete
}

\author{
Jee-Sang Kim, and Chan Hyuk Park \\ Seokyeong University, Civil and Architectural Engineering Department, Republic of Korea \\ e-mail: zskim@skuniv.ac.kr / chanhyouk12@naver.com
}

\begin{abstract}
The verification of serviceability of concrete structures such as crack widths, crack spacings and deformations requires more information on the composite behaviors between concrete and reinforcements. Among them, the investigation of crack widths and spacings is based on the tension stiffening effects. In this paper, the tension stiffening effect of high strength concrete members with compressive strength of 80 and $100 \mathrm{MPa}$ reinforced by D13 are investigated experimentally. The experimental results of this study revealed that the tension stiffening effects of smaller diameter reinforcement (D13) is more distinct than those in larger diameter reinforcement (D10). The reduction of tension stiffening effects in high strength concrete disappears for smaller diameter reinforcement. A modified tension stiffening factor that can be used for high strength concrete is proposed based on experimental results.
\end{abstract}

Keywords: Tension stiffening, high strength concrete, tensile member, cover thickness.

\section{Introduction}

Researches on the high strength and high performance of concrete is actively being carried out and application examples are also increasing. As the strength and performance of the concrete have been improved, it is possible to reduce the sectional dimensions and the total weight of the structure. Generally, when designing a reinforced concrete member, the role of concrete in the tensile region is usually ignored and only the equilibrium condition of force is mainly considered. However, from the viewpoint of macroscopic scale, it is increasingly necessary to consider not only the equilibrium condition of force but also the deformation compatibility.

When crack occurs in a concrete tensile member reinforced with reinforcing bars, the stress is redistributed on the crack face due to the difference in rigidity of the two materials. In the cracked section, the reinforcing bars are responsible for all the tensile forces due to the applied load. However, as the load is increased, the cracks are continuously formed, and the concrete between the cracked ends will bear part of the tensile force transmitted from the reinforcing bars by adhesion. The tension stiffening effect is a phenomenon in which the stiffness of reinforcing bars increases or the strain or stress decreases due to the contribution of concrete between cracks [1]. It is an important factor in evaluating the performance of the concrete that will bear the tensile force between the cracked sections, such as crack widths and deflections, affecting the stiffness and effective secondary moment of inertia [2].

The purpose of this study is to understand the tension stiffening effects when applied to high strength concrete. Direct tensile tests were carried out with the thickness of cover and the strength of concrete as variables. Using the experimental results obtained in this study, the tension stiffening effect was determined by the cover thickness and by the strength of concrete, and the tensile reinforcement coefficient was corrected. 


\section{Theoretical Backgrounds}

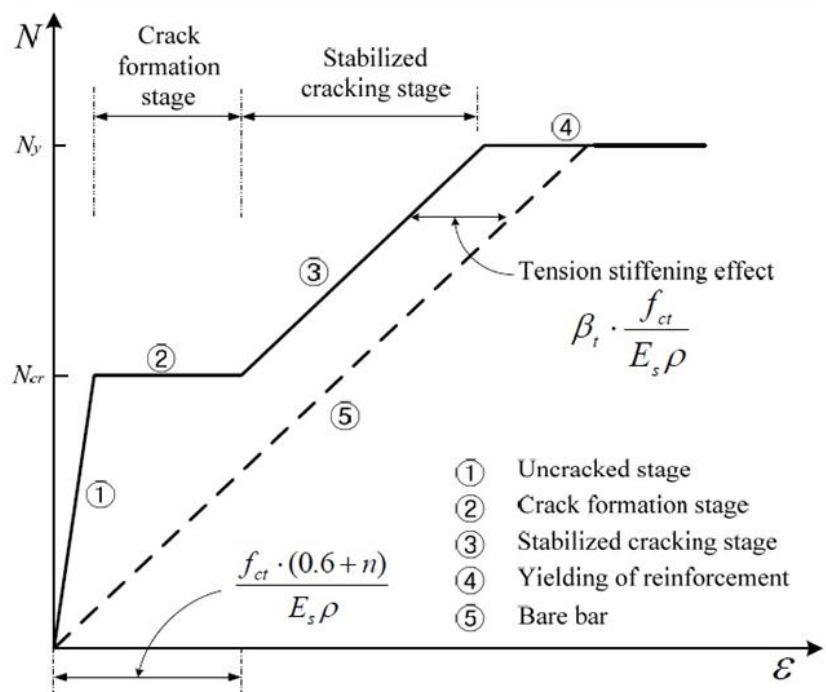

Fig. 1 Load-Strain Relation of Tensile Specimen [3]

In a cracked cross section, all tensile forces are balanced by steel only. However, between adjacent cracks, tensile forces are transmitted from the steel to surrounding concrete by bond stress. The contribution of concrete may be considered to increase the stiffness of tensile reinforcement, which is called tension stiffening as shown in Fig.1. If the tension stiffening effect is neglected, the stiffness of a reinforced concrete bar or a structural member is underestimated. It is defined as the mean strain function of the reinforcing bars shown in Fig. 1 based on the direct tensile test results. When calculating the tension stiffening effect in this way, distinction should be made between the crack formation stage and stabilized cracking stage.

(a) uncracked

(b) crack formation stage

$$
\varepsilon_{s m}=\varepsilon_{s 1}
$$

$$
\varepsilon_{s m}=\varepsilon_{s 2}-\frac{\beta_{t}\left(\sigma_{s}-\sigma_{s r 1}\right)+\left(\sigma_{s r n}-\sigma_{s}\right)}{\sigma_{s r n}-\sigma_{s r 1}}\left(\varepsilon_{s r 2}-\varepsilon_{s 1}\right)
$$

(c) stabilized cracking stage

$$
\varepsilon_{s m}=\varepsilon_{s 2}-\beta_{t}\left(\varepsilon_{s r 2}-\varepsilon_{s e 1}\right)
$$

(d) post-yielding

where, $\varepsilon_{s 1}$ is the strain of reinforcement in uncracked concrete, $\varepsilon_{s 2}$ is the strain of reinforcement in the crack, $\varepsilon_{s r 1}$ is the strain of reinforcement of zero slip under cracking forces reaching $f_{c t m}(t), \varepsilon_{s r 2}$ is the strain of reinforcement at the crack under cracking forces reaching $f_{c t m}(t)$; if the internal forces are lower than or equal to the cracking forces (e.g. in a working joint), $\varepsilon_{s y}$ is the strain at yield strength, $\sigma_{s}$ is the steel stress in the crack, $\sigma_{s r 1}$ is the steel in the crack, when first crack has formed, $\sigma_{s r n}$ is the steel stress in the crack, when stabilized crack pattern has formed(last crack). Also, $\beta_{t}=0.4$ for short-term loading (pure tension), $\beta_{t}=0.25$ for longterm or repeated loading (pure tension). Here, the concept of mean strain $\varepsilon_{s m}$ of steel bars is defined by the method as follows in the crack stabilization stage after cracking occurs [1]. To simplify this

$$
\varepsilon_{s m}=\varepsilon_{s o}-\beta_{t} \frac{f_{c t}}{E_{s} \rho}
$$

Equation (4) is a simplified expression based on the results of experimental results [4]. The relation includes the effect of the cover thickness and concrete compressive strength on the tension stiffening effect but not the splitting cracks.

As a result of the experimental study, the tension strengthening effect decreases when splitting cracks occur in tensile members [5],[6]. The effect of splitting cracks should be considered when the $c / d_{b}$ of tensile members 
is less than 2.5. The results of the study on the tension stiffening effect of the high strength concrete showed that it decreased as the strength of concrete increased [2].

\section{Experiments}

The test specimens in this study were axially loaded direct tension members with a length of $700 \mathrm{~mm}$, containing single $13 \mathrm{~mm}$ bars of yield stress $420 \mathrm{MPa}$ at the centers of specimens. The cross-sectional area of the specimen was kept constant of $10000 \mathrm{~mm}^{2}$ in all specimens to consider the ratio of cover thickness to the bar diameter $\left(\mathrm{c} / \mathrm{d}_{\mathrm{b}}\right)$ between 1.5 and 3.5 in 0.5 increments. The compressive strength of the concrete was set to $80 \mathrm{MPa}$ and $100 \mathrm{MPa}$. According to the level of the target strength, the types of the concrete was SC80(80Mpa), and SC100(100Mpa), and the compressive strength test results were measured as $\mathrm{f}_{\mathrm{c}}=82.4 \mathrm{Mpa}$ for SC 80 and $\mathrm{f}_{\mathrm{c}}=$ $103.5 \mathrm{Mpa}$ for SC100, and the required compressive strength was obtained by a standard test with cylinder of a diameter $100 \mathrm{~mm}$ and a height of $200 \mathrm{~mm}$. The concrete mix design is shown in Table I.

TABLE I: Mixture Design of Concrete $\left(\mathrm{Kg} / \mathrm{m}^{3}\right)$

\begin{tabular}{|c|c|c|}
\hline Constituents & SC 80 & SC 100 \\
\hline W/B (\%) & 0.225 & 0.2 \\
\hline S/A (\%) & 0.42 & 0.42 \\
\hline W & 150 & 165 \\
\hline OPC & 466 & 577 \\
\hline BS & 133 & 165 \\
\hline FA & 66.7 & 0 \\
\hline Sand & 647 & 570 \\
\hline Agg & 898 & 792 \\
\hline SP & 6.667 & 18.15 \\
\hline
\end{tabular}

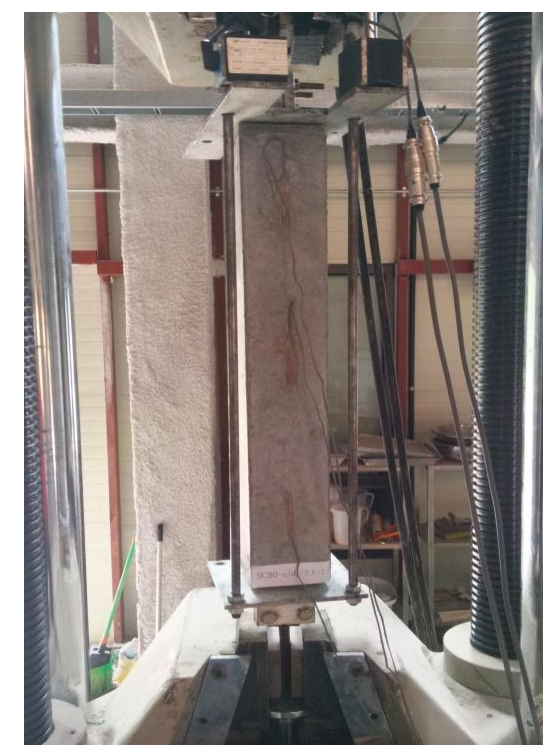

Fig. 2 Test settings

A displacement control method was employed and the longitudinal elongation between the each of specimen was measured as in Fig.1, with two LVDTs mounted at each corner. The load - strain relationship was investigated by measuring the strain of the steel and using the mean value. The cracks observed during the loading were marked and used in investigating the overall cracking behaviour.

\section{Results and discussions}

\subsection{Tension stiffening effects}

To examine the influence of the ratio of cover thickness to the bar diameter, the load-strain relation measured in the experiment is summarized in Fig. 3 and compared with the current design standard MC 2010[3] for the compressive strength of SC 80. Three specimens were fabricated for various ratios of cover thickness to the bar diameter $\left(\mathrm{c} / \mathrm{d}_{\mathrm{b}}\right)$ of $80 \mathrm{MPa}$ and representative values were obtained. A total of 15 specimens were fabricated for each 5 cover thickness ratios, 1.5,2, 2.5, 3 and 3.5. When ratio of cover thickness to the bar 
diameter $\left(c / d_{b}\right)$ is relatively low, 1.5 and 2 , splitting crack occurs first like conventional normal concrete, even though the concrete strength is increased to $80 \mathrm{MPa}$. On the other hand, in the case of the member having $2.5 \mathrm{c} / \mathrm{d}_{\mathrm{b}}$ or more of which the ratio of the cover thickness to the bar diameter $\left(\mathrm{c} / \mathrm{d}_{\mathrm{b}}\right)$ which were sufficiently secured, the value exceeding MC 2010 were obtained. This suggests that it is necessary to modify the tensile enhancement coefficient which is improved as the cover thickness is changed.

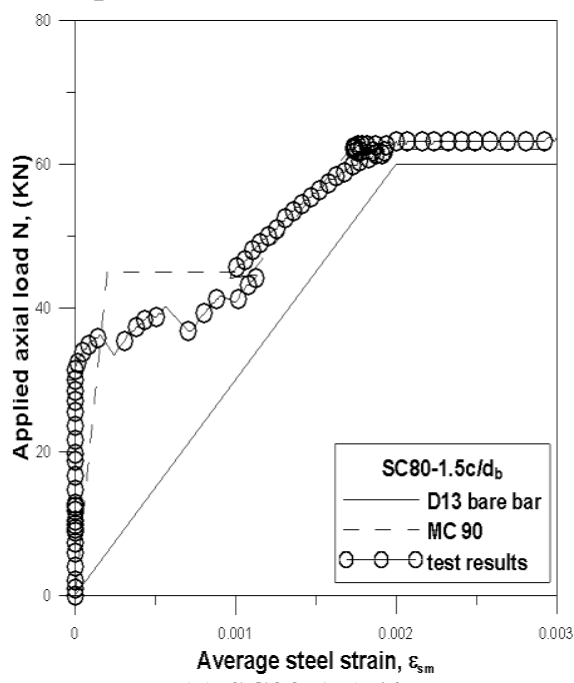

(a) $\mathrm{SC} 80-1.5 \mathrm{c} / \mathrm{d}_{\mathrm{b}}$

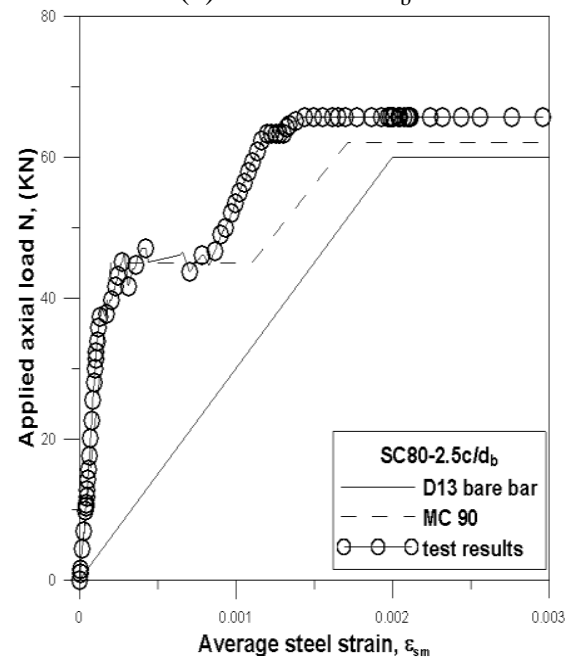

(c) $\mathrm{SC} 80-2.5 \mathrm{c} / \mathrm{d}_{\mathrm{b}}$

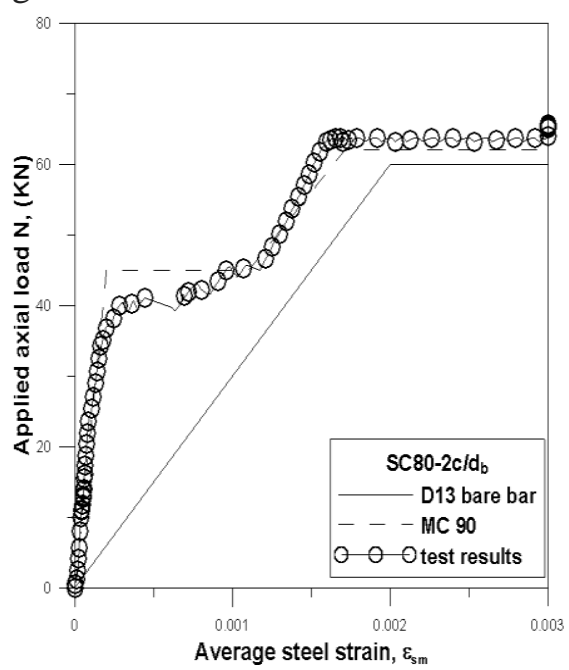

(b) $\mathrm{SC} 80-2 \mathrm{c} / \mathrm{d}_{\mathrm{b}}$

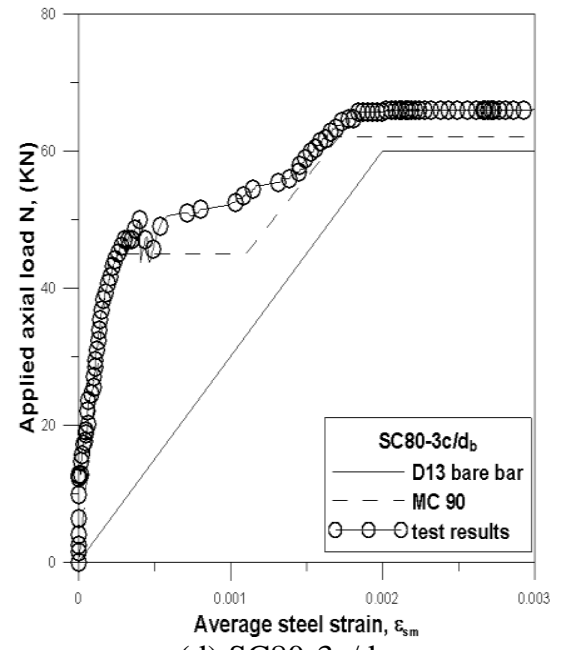

(d) $\mathrm{SC} 80-3 \mathrm{c} / \mathrm{d}_{\mathrm{b}}$

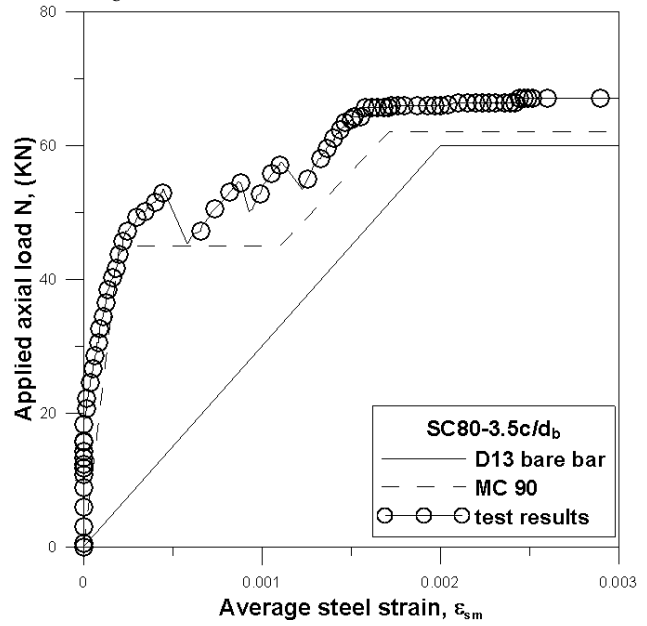

(e) $\mathrm{SC} 80-3.5 \mathrm{c} / \mathrm{d}_{\mathrm{b}}$

Fig. 3 Load-average steel strain relations for SC80 
To examine the effect of bar diameter on tension stiffening, a comparison was made between the same compressive strength and the cover thickness ratio using D19 as reinforcement, which was obtained from other researchers [2] in Fig.4. Design standard values are shown and compared with each test specimen. It is shown that, in the case of D19 reinforcement, the splitting crack load is close to the transverse crack load even when the cover thickness is high, and the tensile strengthening effect is reduced. From the results, it can be said that the high strength concrete using D13 is superior to the high strength concrete using D19 in view of tension stiffening effect. This means that as the concrete strength increases, the rebar diameter decreases and the slip amount decreases as the bond strength increase [6],

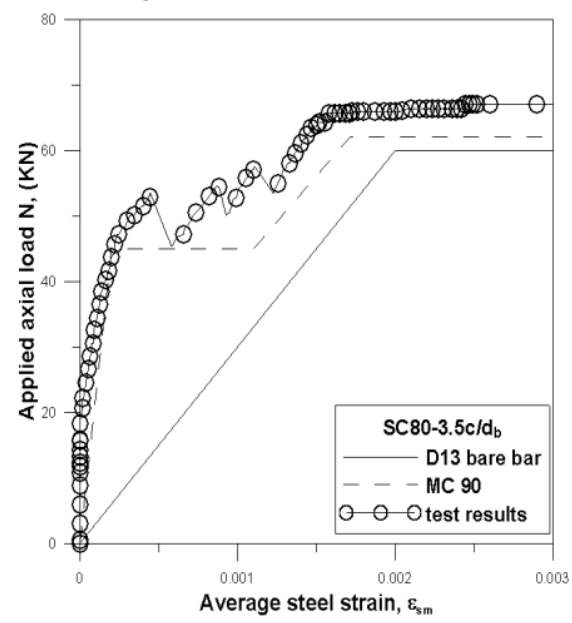

(a) $\mathrm{D} 13-\mathrm{SC} 80-3.5 \mathrm{c} / \mathrm{d}_{\mathrm{b}}$

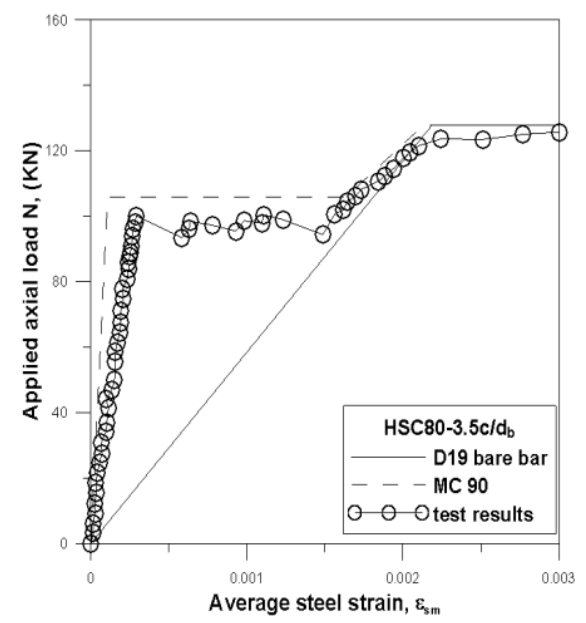

(b) $\mathrm{D} 19-\mathrm{SC} 80-3.5 \mathrm{c} / \mathrm{d}_{\mathrm{b}}$

Fig. 4 Effect of bar diameter on tension stiffening

Three specimens were fabricated for various ratios of cover thickness to the bar diameter $\left(\mathrm{c} / \mathrm{d}_{\mathrm{b}}\right)$ of $100 \mathrm{MPa}$ and representative values were shown as in Fig. 5. Comparing Fig.3 and Fig. 5, it can be said that both SC80 and SC100show the similar tendency for various cover depth ratios. In the case of 1.5 and 2 with lower cover thickness ratios, the value was smaller than the predicted cracking load in the design standard. In addition, the specimen with the cover thickness of 2.5 or more reached a crack generation load earlier than that in the design standard, but after the crack occurred, the tensile strengthening effect was higher than the design standard (CEBFIP Model Code 2010). This means that the higher the strength of the concrete after the first cracking, the higher the capacity of stress redistribution as the bond transfer length $\left(l_{t}\right)$ increases with the increase of the bond stress. Therefore, it can be concluded that the D-section (distributed zone) is getting longer in the high-strength concrete.

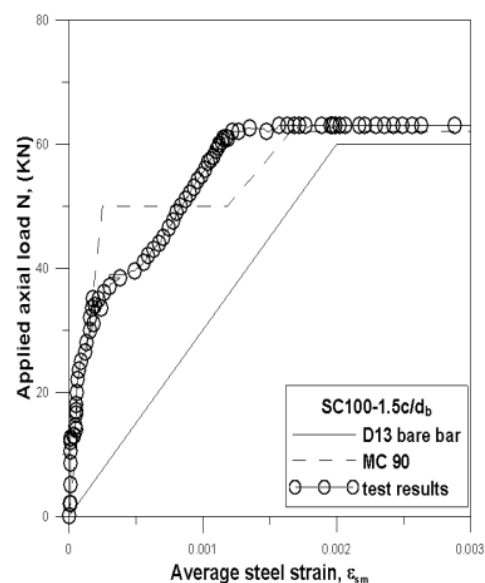

(a) $\mathrm{SC} 100-1.5 \mathrm{c} / \mathrm{d}_{\mathrm{b}}$

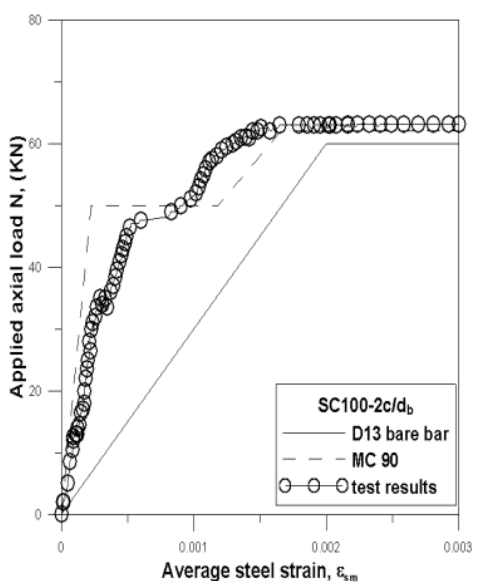

(b) $\mathrm{SC} 100-2 \mathrm{c} / \mathrm{d}_{\mathrm{b}}$ 


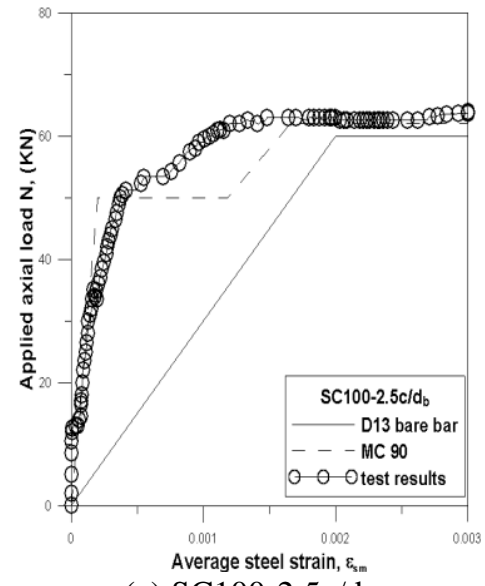

(c) $\mathrm{SC} 100-2.5 \mathrm{c} / \mathrm{d}_{\mathrm{b}}$

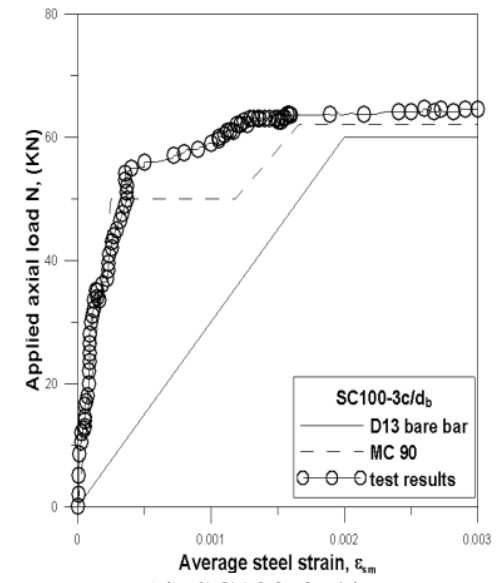

(d) $\mathrm{SC} 100-3 \mathrm{c} / \mathrm{d}_{\mathrm{b}}$

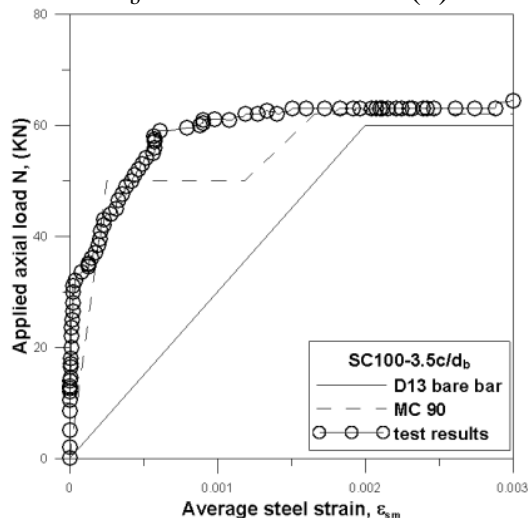

(e) $\mathrm{SC} 100-3.5 \mathrm{c} / \mathrm{d}_{\mathrm{b}}$

Fig. 5 Load-average steel strain relations for SC100

\subsection{Crack Generation Load Comparison}

The crack resistance of high - strength concrete was verified by comparing crack generation load of specimen of normal strength concrete $\left(\mathrm{f}_{\mathrm{c}}=30 \mathrm{MPa}\right)$ using D13 reinforcing steel and crack generation load of high strength concrete (SC80). The effect of splitting crack, which is a factor that inhibits the tension stiffening effect, was confirmed by this study. In addition, the predicted transverse cracking loads with various compressive strengths were compared.

TABLE II: Comparison of Transverse Cracking Load $\mathrm{N}_{\mathrm{tr}}$

\begin{tabular}{|c|c|c|}
\hline \multirow{2}{*}{$\mathrm{c} / \mathrm{d}_{\mathrm{b}}$} & \multicolumn{2}{|c|}{ Transverse cracking load N $\mathbf{N}_{\text {tr }}(\mathbf{K N})$} \\
\cline { 2 - 3 } & NC 30 & 30 \\
\hline 1.5 & - & 34 \\
\hline 2 & 14 & 37 \\
\hline 2.5 & 19 & 42.5 \\
\hline 3.5 & 17 & 47 \\
\hline
\end{tabular}

Table II compares the crack initiation loads of normal and high strength concrete through the experimental results. Table III compares the predicted transverse cracking loading with the actual measured transverse cracking loading according to compressive strength. For NC 30, the expected transverse crack initiation loads are $\mathrm{N}_{30}=28 \mathrm{KN}$ and for $\mathrm{SC} 80$ the expected crack $\mathrm{N}_{80}=45 \mathrm{KN}$. The actual lateral crack initiation load according to the cover thickness for the predicted transverse crack occurrence load is shown in Fig. 6

TABLE III: Comparison of Transverse Cracking Load Ratio

\begin{tabular}{|c|c|c|}
\hline \multirow{2}{*}{$\mathrm{c} / \mathrm{d}_{\mathrm{b}}$} & \multicolumn{2}{|c|}{ Transverse cracking load ratio } \\
\cline { 2 - 3 } & $\mathrm{NC} 30$ & $\mathrm{SC} 80$ \\
\hline 1.5 & - & 0.75 \\
\hline 2 & 0.5 & 0.82 \\
\hline 2.5 & 0.68 & 0.98 \\
\hline 3 & 0.61 & 1.04 \\
\hline 3.5 & 0.85 & 1.02 \\
\hline
\end{tabular}




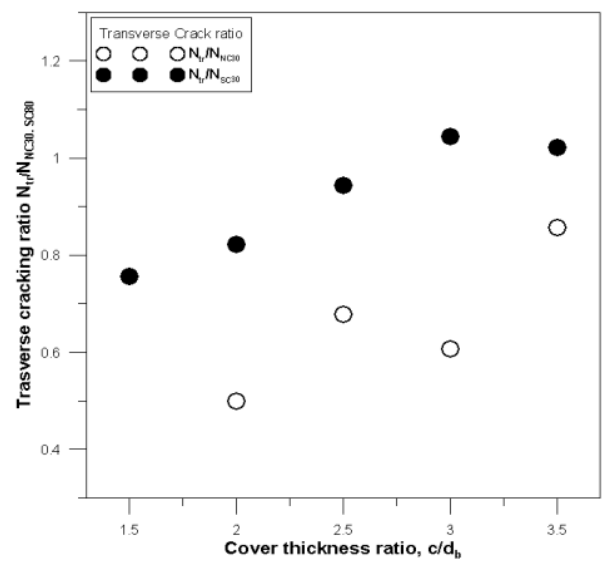

Fig. 6 Transverse cracking load ratio for SC80 and SC100

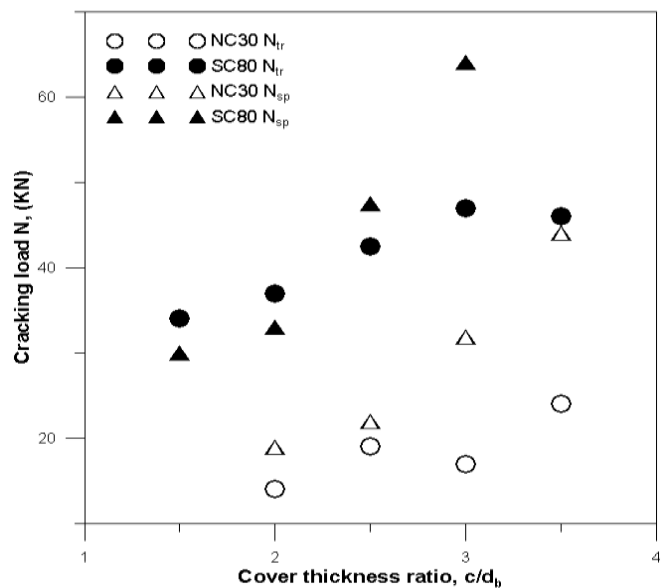

Fig. 7 Cracking loads for normal and high strength concrete

The crack generation loads of normal strength concrete and high strength concrete were compared in Fig. 7. In normal strength concrete, the transverse crack initiation load is observed before the splitting crack initiation load, so there is no problem in showing the tension stiffening effect. However, it is hard to see that the tension stiffening effect appears again as the expected transverse crack occurrence load $\left(\mathrm{N}_{\mathrm{tr}}\right)$ is less than the result. On the other hand, in the case of high - strength concrete, the splitting crack was preceded by the cover thickness of 1.5 and 2, and the tension stiffening effect could not be exhibited again. However, when the ratio of cover thickness to the bar diameter $\left(\mathrm{c} / \mathrm{d}_{\mathrm{b}}\right)$ is more than 2.5 , the transverse cracks precede the split cracks, which is close to the predicted transverse cracking loads. From the results, it was found that high - strength concrete using D13 reinforcing steel can prevent splitting cracking $\left(\mathrm{N}_{\mathrm{sp}}\right)$, which is an obstacle to the tension stiffening effect, if the cover thickness is sufficiently secured. The tendency that the splitting cracking load $\left(\mathrm{N}_{\mathrm{sp}}\right)$ increases with the cover thickness increases is similar in high strength concrete and normal strength concrete.

\section{Determination of tension stiffening factors}

The value defined as the tensile strength test factor at MC 2010 has a fixed $\beta_{t}$ value of 0.4. However, the experimental results show that the tensile strengthening effect varies depending on the ratio cover thickness to the bar diameter $\left(\mathrm{c} / \mathrm{d}_{\mathrm{b}}\right)$. Experimental results of members of 1.5 and 2 with insufficient the ratio cover thickness to the diameter bars $\left(\mathrm{c} / \mathrm{d}_{\mathrm{b}}\right)$ showed a value of less than 0.4 and more than 0.4 in case of 2.5 or more specimen with sufficient cover thickness. This means that there is a difference between the current design criteria and the experimental value and that appropriate modification is required to reflect the high-strength concrete using D13 reinforcing bars.

For this purpose, the tension stiffening factor of high - strength concrete by cover thickness were analyzed using the ratio of the strain and the applied load of the reinforced concrete embedded in the concrete measured 
through direct tensile test of high - strength concrete. For this purpose, the coefficient of the CEB-FIP Model Code 2010 [3], which specifies the tension stiffening effect, was verified and the influence of the cover thickness was examined. The time when the first crack occurred for the various cover thicknesses was determined, and the tension stiffness coefficient calculated from the crack load to the rebar yield strength was calculated by the arithmetic average of the tensile stiffness coefficients according to the increase of the working load. As an example, the value of SC80 cover thickness $\left(\mathrm{c} / \mathrm{d}_{\mathrm{b}}\right)$ is 3.5, as shown in Fig. 7

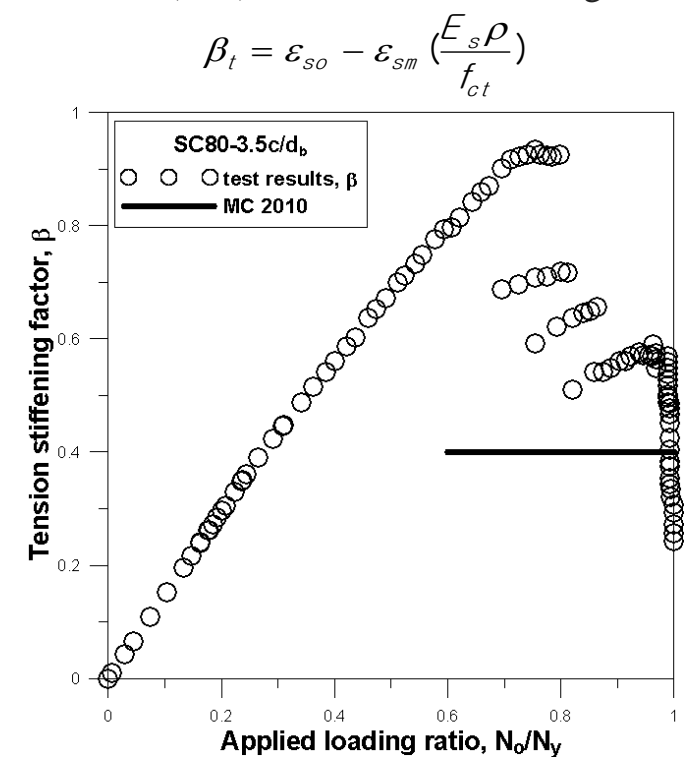

Fig. 8 Comparison of design criteria and tension stiffening factor, $\beta$

Regarding these values, the regression analysis was performed for varying ratios of the cover thickness to the rebar diameter, and the tensile reinforcement coefficient formula, which can be applied to the linear tension stiffening effect model according to the MC 2010, was obtained as follows.

$$
\beta_{t}=0.4\left(\frac{c / d_{b}}{2.4}\right)^{0.5}
$$

The coefficient of determination of the reliability of the tensile stiffness coefficient equation with the ratio of the cover thickness to the diameter of the rebar was high. The tensile strength of high - strength concrete with the cover thickness as a variable was obtained from this equation, and it was confirmed that there is not a large difference when the modified coefficient and actual measured value are compared. Using (6), the relationship between the cover thickness ratio and the results of the previous studies was compared in Fig. 9.

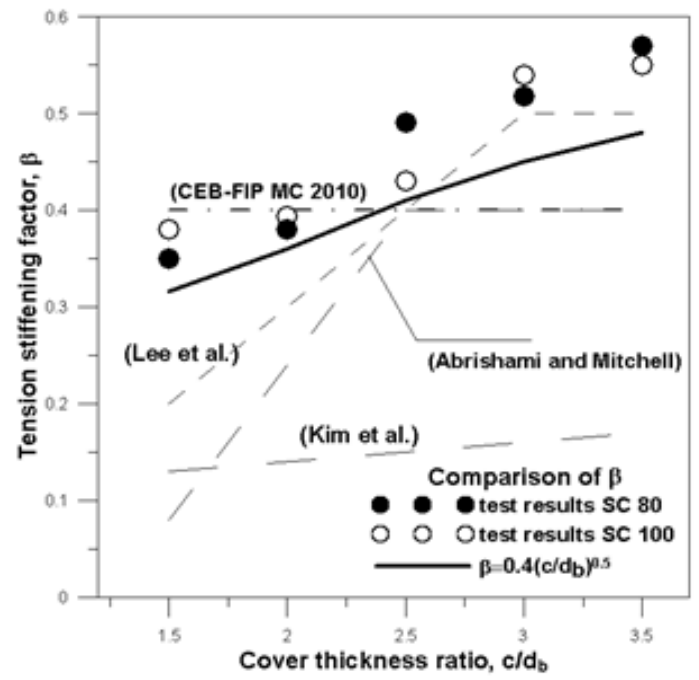

Fig. 9 Proposed tension stiffening factor for high strength concrete

The relationship between the coating thicknesses from 1.5 to 3.5 was confirmed, and the tensile strength of $t$ 
he proposed high strength concrete is close to that of SC80 and SC100. It predicts the value more accurately than the existing research results that are based on the same standard. The results are similar to those of the previous research [5], [ 6]. In addition, when D19 reinforcing bars were used, high values of tensile strength values of hig h strength concrete using D19 reinforcing bars were found [2]. This is because the higher the strength of the high -strength concrete is, the lower the diameter of the rebar is, the higher the adhesive stress and the subsequent spli tting cracks occur [7]. The tension stiffness factor determined by Equation. (3) can be used to derive the predicti ve value of the tensile reinforcement effect of high strength concrete considering the change of coating thickness using D13 reinforcement.

\section{Conclusions}

This paper focuses on understanding the effect of tension stiffening in the stabilization phase of cracks, which is the load bearing stress applied to actual structures. For this purpose, direct tensile test specimens with compressive strengths of $80 \mathrm{MPa}$ and $100 \mathrm{MPa}$ were prepared and subjected to direct tensile tests. For this purpose, direct tensile test specimens with compressive strengths of $80 \mathrm{MPa}$ and $100 \mathrm{MPa}$ were prepared and D13 reinforcing bars were placed at the center of the specimens. The conclusions are obtained as follow.

- $\quad$ Specimens with high - strength concrete using D13 reinforced concrete produced splitting cracks when the cover thickness was not sufficiently secured, which is one of dominant factors determine the tension stiffening effect.

- The predicted transverse cracking loads of the high strength concrete were close to those of the normal strength concrete.

- The tension stiffening effect was improved as the reinforcing bar diameter of high strength concrete was smaller. Also, as the strength of the concrete increases, the strength of the bond increases as the diameter of the steel reinforcement decreases.

Tension stiffening effect of high strength concrete was grasped. The tension stiffening coefficient of high strength concrete was introduced through this study. This shows that the tension stiffening of the tensile member is predicted more accurately after cracking.

\section{References}

[1] CEB-FIP, CEB-FIP Model Code 1990, Comite Euro-International Du Beton, Paris, 1991, pp. 87-110

[2] Woo-Kim, Gi-Yeol Lee, Hwan-Suk Yum, Bond Characteristics and Cracking Behavior in High-Strength Concrete Tensile Members (1) - Modeling of Tension Stiffening Effect, Journal of the Korean Society of Civil Engineers A, Vol. 21, No. 5-A 2001, pp. 687-697 [in Korean]

[3] Fib, fib Model Code 2010, First complete draft - Volume 2, Fédération internationale du béton, 2010, Switzerland, pp. 137 140

[4] Fritz Leonhardt, Crack Control in Concrete Structures, IABSE Surveys No. S-4/77, Zurich, 1977, 26 pp

[5] Homayoun H. Abrishami and Denis Mitchell, Influence of Splitting Cracks on Tension Stiffening, ACI Structural Journal, Vol. 93, No. 6, 1996, pp. 703-710

[6] Gi-Yeol Lee, Min-Joong Kim, Woo Kim, Hwa-Min Lee, Tension Stiffening Effect Considering Cover Thickness in Reinforced Concrete Tension Members, Journal of the Korea Concrete Institute, Vol. 23, No. 6, 2011, pp.791-797 [in Korean]

[7] Moon-Sung Lee, Tae-Seok Seo, Young-Sook Roh, Experimental Study on Bond Properties of High Strength RC Flexural Member at Stabilized Crack Stage, Journal of the Architectural Institute of Korea structure \& Construction, Vol 27, No. 9, 2011, pp. 37-44 [in Korean]

[8] ACI Committee 224, Cracking of Concrete Members in Direct Tension, ACI Journal, Vol. 83, No. 1, 1986, pp. 224.2R-86

[9] Kelvin Fields, Peter H. Bischoff, Tension Stiffening and Cracking of High-Strength Reinforced Concrete Tension Members, Vol. 101, No. 4, 2004, pp. 447-456 